\title{
Efficacy and Toxicity Study of Nardostachys Jatamansi DC and Valeriana Wallichii DC in Sleep Disorders
}

\author{
Sweta Jha ${ }^{1 *}$, Nirmla Devi Thakur ${ }^{2}$ \\ ${ }^{1}$ Assistant Professor, Department of Botany, Dr. RMLS College, Babasaheb Bhimrao Ambedkar Bihar \\ University, Muzaffarpur, India \\ ${ }^{2}$ Sunandan Divatia School of Science, SVKM's NMIMS, Mumbai, India \\ *Corresponding author: skoundilya@gmail.com
}

\begin{abstract}
Background: Sleep disorders are common in general population and adversely affects the health related quality of life. Many people do not want to rely upon allopathic drug easily available over the counter because of their side effects. Cases of sleep disorders have exponentially increased during pandemic (Covid -19) and new term Covid-somnia have been coined for the same. Two Perennial herbs from Valerianeaceae family i.e Nardostachys jatamansi DC and Valeriana wallicii DC which are known as high value medicinal plants were selected for the study. Nardostachys jatamansi DC is used in the treatment of epilepsy, hysteria, convulsive ailments whereas rhizome of Valeriana wallicii DC have shown anxiolytic, stress releasing and antidepressant effects.

Materials and Methods: The present study was undertaken to evaluate the efficacy and toxicity of the selected herbs for Sleep Disorders. A dose dependent Phenobarbitone - induced sleep time measurement study was performed. Further measure the effect of motor coordination, walking assay was performed.

Results and Conclusions: Results of acute toxicity study and Irwin test indicated that selected extracts of Nardostachys jatamansi DC and Valeriana wallichii are safe. Further dose dependent Phenobarbitone - induced sleep time measurement study showed significant increase in selected three doses for this study $(125,250,500 \mathrm{mg} / \mathrm{kg}$ body weight compared to control. The result of the study demonstrated that oral administration of extracts produced a dose-dependent decrease in sleep latency and increase in sleep duration in mice treated with extracts. These extracts exhibited a non- significant reduction in the number of foot slips in non-dose dependent manner relative to Phenobarbitone treated group.
\end{abstract}

Keywords: Irwin test, Nardostachys jatamansi DC, Phenobarbitone, Sleep disorder, Valeriana wallichii DC.

\section{Introduction}

Sleep is a complex neurological process that is important in mammalian homeostasis and required for survival (Lorton et al. 2006). A good quality and quantity of sleep is very much important for human being and animals. Besides restoring our energy level and rest, a good sleep also helps to maintain our overall physical and mental health. Sleep disorder is the term given to disturbance in sleeping pattern of person or animals in terms of quality or quantity. Due to disturbed sleep there is imbalance between mental and physical functioning which further worsens health condition. With the exponential increase in sleep disorders along with covid-19 pandemic surge, neurologist specialized in sleep disorders have termed it as Covid-somnia. Symptoms of Covid-somia have been reported in many unrelated people who have not even been infected or treated. Psychosomatic illnesses have been found due to fear of process of treatment including social isolation and consequences (Hurley, D. 2020). According to a report from United States patents with Covid-somnia surpassed Covid -19 infections by $14.8 \%$ between February 16 and March 15, 2020 compared with same duration of 2019 (Jing Qi, et al. 2020).

Recently, a study by Rogers and colleagues (Rogers et al.2020) showed the effect of SARS- and MERS-CoV on Psychological conditions during different stages of illness. Along with other psychological illness, different symptoms with varying percentage were observed at different phases of illness such as insomnia (41.9\%), anxiety (35.7\%) and depression $(32.6 \%)$ during acute illness. During post-illness stage, sleep disorder (100\%), anxiety (12.3\%), insomnia $(12.1 \%)$, and depression $(10.5 \%)$ were commonly observed.

Medicines for sleep disorders available in market are less preferred because of its various side effects like dose dependence, withdrawal symptom, tolerance, next day hangover, sedation, dizziness, and psychomotor impairment (Mendelson 2005, Zhang et al. 2010). Many people are turning towards natural remedies for treating sleep disorders like insomnia. According to a survey in America, more than 1.6 million adults use alternative medicines to treat sleep disorder as they are easily available, without many side effects, less costly and available without medical prescription (Pearson et al. 2006). Recently a neurologist and Assistant Professor at university of Toronto mentioned general prescribed medicines for quick treatment of Covid-somnia are zolpedem or benzodiazepines but with limitations and restrictions as have long term effects on sleep quality as well as cognition and also reduce slow wave sleep (Hurley, D. 2020). 
Ethno botanical survey has shown various medicinal properties of Nardostachys jatamansi DC. It is commonly known as Jatamansi and is distributed in sub-alpine to alpine regions at an altitude of $3000-5000 \mathrm{~m}$. It is used in the treatment of epilepsy, hysteria, convulsive ailments, palpitations of the heart, diseases of the eye, itches, boils, swellings, diseases of the head, hiccough etc. (Dweck,1996). Other use includes improving the complexion, increasing the luster of the eye, promoting the growth and ailments of the hair for blackness (Jayaweera 1982), and depressant activity (Indurwade \& Biyani 2000).

Rhizome of Valeriana wallicii DC commonly known as Tagar. It is hairy perennial herb, growing in temperate Himalayas from Kashmir to Bhutan and Khasia hills up to an altitude of 3,000 m. Tagar have shown anxiolytic, stress and antidepressant effects (Bhattacharyya et al. 2007). It has also effect on cognitive performance (Gerhard et al. 1996). It has also been shown that GABA-A receptor modulation is related to valerenic acid (Trauner et al. 2008). Various other activities like hepato-protective (Shariq Naeem Syed 2014), gastrointestinal and cardiovascular disorder (Gilani et al. 2005) have also been mentioned.

\section{Materials and Methods}

The roots and rhizomes of Nardostachys jatamansi DC and Valeriana wallichii DC were collected from herbal market of Mumbai, India. Specimen samples were authenticated by National Botanical Research Institute, Lucknow, India.The voucher samples were deposited at National Botanical Research Institute, Lucknow, India. Roots /rhizomes were shade dried, powdered by mechanical grinder and coarse powder was further passed through sieve of mesh size of 40 for uniform particle size.The powder obtained was subjected to hexane and methanolicextractions using soxhlet method. Extracts acquired were labeled as NJME for Nardostachys jatamansi DC methanolic extract and NJHE for hexane extracts. Similarly, methanolic extract of Valeriana wallichii DC was labeled as VWME and hexane extracts as VWHE).

\section{A. Experimental animals}

Male swiss albino mice (27-30 g) obtained from Central Animal Facility, NMIMS University, Mumbai, India, were used for the study. Animals were housed in individual polycarbonate cages in a well-ventilated room under an ambient temperature of $26 \pm 2{ }^{\circ} \mathrm{C}$ and $40 \%-65 \%$ relative humidity, with artificial photoperiod 12-hour light dark cycle. Experimental animals were provided with standard rodent pellet diet and purified water ad libitum. Animals were acclimated for 7 days to the laboratory conditions prior to the initiation of the studies. A guideline for the care and use of laboratory animals (Institute of Laboratory Animal Resources, National Academic Press 1996; NIH publication number \#85- 23, revised 1996) was strictly followed throughout the study. All study protocols were approved by the Institutional Animal Ethics Committee (IAEC) of SPPSPTM, NMIMS University, Mumbai, India.

\section{B. Experimental Design}

1) Sub-Acute toxicity study

The toxicity of extracts was evaluated in mice using the OECD guidelines 420 (OECD-420 2002) with slight modifications. Vehicle used for administration of extracts was 0.5\% Carboxy Methyl Cellulose (CMC), prepared in Distilled water. Vehicle was administered to control group. Extracts of Nardostachys jatamansi DC (NJME, NJHE) and Valeriana wallichii DC (VWME, VWHE) for administration were prepared in $0.5 \%$ CMC shortly before experiment. Maximum dose administered to animals was $2 \mathrm{ml} / 100 \mathrm{~g}$ body weight. Swiss albino male mice were randomly divided into five groups representing four extracts and one control with six animals in each group. The extracts were administered orally at doses of $2,000 \mathrm{mg} / \mathrm{kg}$ of bodyweight. The general behavior of the mice was monitored continuously for one hour after dosing, and then periodically for the first 24 hours with special attention given during the first 4 hours of dosing thereafter, daily for a total of 14 days. Animals were observed for any mortality or any changes in the normal activity.

2) Irwin Test

The Irwin test is a systematic observational procedure for assessing and scoring the effects of psychotropic drugs on the behavioral and physiological state of rodents. This test is particularly suitable when done at an early stage of drug development. Irwin test helps in (a) screening and selection of compounds against unwanted psychological effects, (b) To understand the mechanism underling these psychological effects, (c) help improve the structure-activity relationship and (d) possibly reveal novel therapeutic effects. By using an appropriate dose range for each test molecule, it is possible to obtain information on its pharmacological profile, on the intensity and the duration of its effects, and on the specificity of these effects. This test was performed with male mice (20-35 g) that were assigned to four randomized groups of 6 animals each for each extract, and one group for control. The groups were observed at 30,60,120, and $180 \mathrm{~min}$. following the oral administration of the vehicle as $0.5 \% \mathrm{CMC}$ as control and 125 , 250 , and $500 \mathrm{mg} / \mathrm{kg} \mathrm{b.w}$. of extracts. At each observation time, 22 parameters were scored using a rigorous standardized procedure based on the one described by Irwin test method. These parameters are distributed as follows: 10 items for the behavioral profile (Spontaneous activity, body position, locomotive activity, transfer arousal, touch escape, positional passivity, toe pinch, corneal, pinna, and tail elevation); 7 items for the neurological profile (body tone, grip strength, righting reflects, hypotonic gait, tremors, twitches, and convulsions); 5 items for the autonomic profile (palpebral closure, diarrhoea, piloerection, hypothermia, and skin Color ) (Irwin 1968).

3) Phenobarbitone induced sleeping behavior

All plant extracts were evaluated using the pentobarbitalinduced sleep test in Swiss albino mice. For selection of reference drug, we took two reference drug (Alprazolam from 
cipla and phenobarbitone from Piramal health care) which are used as sleeping pills and acts through GABA receptor. Drugs were given orally to animals at four different dose levels i.e. 30, 6090 and $120 \mathrm{mg} / \mathrm{kg}$ b.w. along with control $0.5 \%$ CMC. Each group was showing variable response at different dose level. Group dosed with Alprazolam gave positive response although at a very high dose i.e. $120 \mathrm{mg} / \mathrm{kg}$ b.w. and sleep latency was observed after three hours. In case of Phenobarbitone, sleep behavior was observed within an hour and extended for an hour at $60 \mathrm{mg} / \mathrm{kg}$ b.w. Thus, Phenobarbitone at $60 \mathrm{mg} / \mathrm{kg}$ b.w. was selected for further studies along with four extracts viz NJME, NJHE, VWME, VWHE and $0.5 \% \mathrm{CMC}$ as control. Animals were divided into five group with six animals each Group 1, animal was dosed with $0.5 \%$ CMC Control, Group 2 with 125 $\mathrm{mg} / \mathrm{kg}$ b.w., Group 3 with $250 \mathrm{mg} / \mathrm{kg}$ b.w. Group 4 with 500 $\mathrm{mg} / \mathrm{kg}$ b.w. extract whereas Group 5 was dosed with Phenobarbitone, $60 \mathrm{mg} / \mathrm{kg}$ b.w. Modified method of (Ma et al. 2009) was adapted to perform the Phenobarbitone induced sleep test. All extracts and Phenobarbitone were suspended in 0.5\% CMC. All experiments were carried out between 10:00 a.m. and 5:00 p.m. Animals were fasted for $24 \mathrm{~h}$ prior to the experiment. Test samples (extracts) were administered orally to mice one hour prior to Phenobarbitone oral administration.
Following Phenobarbitone administration animals were placed in separate cage and those animals that were active 15 minute after administration of Phenobarbitone were taken out of the experiment. Each animal was observed for sleep latency and sleeping duration. Observers included for the study, were blind to treatment. The sleep latency is the time taken by animals to fall sleep from the time of Phenobarbitone administration, and sleeping duration is the duration between loss and recovery of righting reflex. Both these parameters of sleep latency and duration of sleep were recorded.

\section{4) Walking Assay}

Walking assay is a very sensitive test to measure motor coordination and effective sedative dose of extracts on experimental animals. The Swiss albino mice were trained to walk from a start platform along a ruler $(60 \mathrm{~cm}$ long and $8 \mathrm{~mm}$ wide) elevated $30 \mathrm{~cm}$ above the bench by metal support to a goal box. Three trials were performed for each mouse to ensure that the mice learnt properly. The mice that successfully walked along the ruler were randomly divided into groups of six mice each. Group-I received 0.5\% CMC (control) whereas Group-II, Group-III and Group-IV received extracts orally at the dose of 125,250 and $500 \mathrm{mg} / \mathrm{kg}$ body weight respectively, Group-V was treated orally with Phenobarbitone ( $60 \mathrm{mg} / \mathrm{kg}$ body weight) only. All extracts were dosed orally for five days. After duration Table 1

General activity and time dose dependent response summery showing average data score for Nardostachys Jatamansi DC Methanolic extract

\begin{tabular}{|c|c|c|c|c|c|c|c|c|c|c|c|c|c|c|c|c|}
\hline \multirow{2}{*}{$\begin{array}{l}\text { NJME } \\
\text { Dose (mg/kgb.w) }\end{array}$} & \multicolumn{16}{|c|}{ Time after administration of different doses of extracts and $0.5 \% \mathrm{CMC}$ to control $(\mathrm{C})$} \\
\hline & $\mathbf{C}$ & 125 & 250 & 500 & $\mathbf{C}$ & 125 & 250 & 500 & $\mathbf{C}$ & 125 & 250 & $\mathbf{5 0 0}$ & $\mathbf{C}$ & 125 & 250 & 500 \\
\hline \multicolumn{17}{|l|}{ Behavioral } \\
\hline spontaneous activity & 4 & 4 & 3.6 & 2.5 & 4 & 4 & 4 & 1.8 & 4 & 4 & 4 & 2 & 4 & 4 & 4 & 4 \\
\hline locomotive activity & 4 & 4 & 3 & 2 & 4 & 4 & 4 & 2 & 4 & 4 & 4 & 3.5 & 4 & 4 & 4 & 4 \\
\hline \multicolumn{17}{|l|}{ Motor-affective response } \\
\hline Transfer arousal & 4 & 4 & 4 & 3 & 4 & 4 & 2.8 & 3 & 4 & 4 & 4 & 4 & 4 & 4 & 4 & 4 \\
\hline \multicolumn{17}{|l|}{ Sensorimotor response } \\
\hline Toe pinch & 4 & 4 & 4 & 3 & 4 & 4 & 3 & 3 & 4 & 4 & 4 & 4 & 4 & 4 & 4 & 4 \\
\hline Corneal & 4 & 4 & 4 & 4 & 4 & 4 & 3.5 & 4 & 4 & 4 & 4 & 2.8 & & & & \\
\hline Pinna & 4 & 4 & 4 & 3 & 4 & 4 & 4 & 3 & 4 & 4 & 3 & 3 & 4 & 4 & 4 & 4 \\
\hline \multicolumn{17}{|l|}{ Posture } \\
\hline Tail elevation & 2 & 2 & 2 & 2 & 2 & 2 & 2 & 2 & 2 & 2 & 2 & 2 & 2 & 2 & 2 & 2 \\
\hline Righting reflects & 0 & 0 & 0 & 0 & 0 & 0 & 0 & 0 & 0 & 0 & 0 & 0 & 0 & 0 & 0 & 0 \\
\hline Hypotonic gait & 0 & 0 & 0 & 0 & 0 & 0 & 0 & 0 & 0 & 0 & 0 & 0 & 0 & 0 & 0 & 0 \\
\hline \multicolumn{17}{|l|}{ CNS excitation } \\
\hline Tremors & 0 & 0 & 0 & 0 & 0 & 0 & 0 & 0 & 0 & 0 & 0 & 0 & 0 & 0 & 0 & 0 \\
\hline Twitches & 0 & 0 & 0 & 0 & 0 & 0 & 0 & 0 & 0 & 0 & 0 & 0 & 0 & 0 & 0 & 0 \\
\hline Convulsions & 0 & 0 & 0 & 0 & 0 & 0 & 0 & 0 & 0 & 0 & 0 & 0 & 0 & 0 & 0 & 0 \\
\hline \multicolumn{17}{|l|}{ Autonomic } \\
\hline Eyes: Palpebral closure & 0 & 0 & 0 & 0 & 0 & 0 & 0 & 0 & 0 & 0 & 0 & 0 & 0 & 0 & 0 & 0 \\
\hline \multicolumn{17}{|l|}{ Secretion Excitation } \\
\hline \multicolumn{17}{|l|}{ Diarrhoea } \\
\hline \multicolumn{17}{|l|}{ General } \\
\hline Piloerection & 0 & 0 & 0 & 0 & 0 & 0 & 0 & 0 & 0 & 0 & 0 & 0 & 0 & 0 & 0 & 0 \\
\hline Hypothermia & & & & + & & & & + & & & & & & & & \\
\hline
\end{tabular}


Table 2

General activity and time dose dependent response summery showing average data score for Nardostachys Jatamansi DC Hexane extract

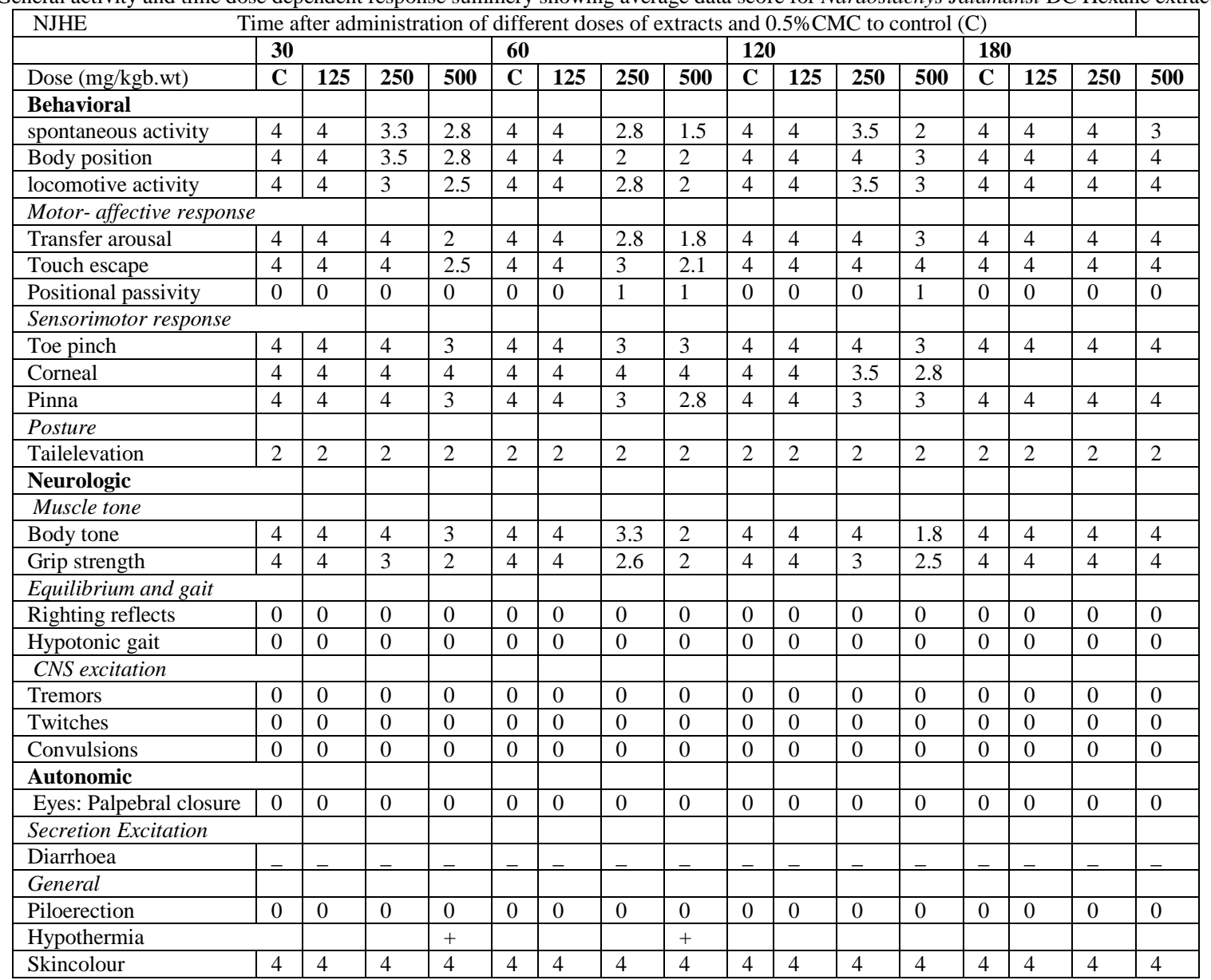

of an hour, each dosed mouse was allowed to walk to the goal box. The duration taken to cover ruler and the number of foot slips was recorded with the aid of a tally counter (Stanley et al. 2005).

\section{Results and Discussion}

\section{A. Toxicity studies}

The extracts were found to be non-toxic up to the dose of $2000 \mathrm{~g} / \mathrm{kg}$ body weight and they did not cause any mortality or symptoms of toxicity through the 14-day period. The animals did not show any changes in the general appearance during the observation period.

In the Irwin test, immediate difference was observed after 30 min in the spontaneous movement of the mice administered with NJME at $250 \mathrm{mg} / \mathrm{kg}$ b.w. and $500 \mathrm{mg} / \mathrm{kg}$ b.w. Also, there was a decrease in the transfer arousal, touch escape and grip strength and increase of positional passivity at $500 \mathrm{mg} / \mathrm{kg}$ b.w dose concentration after $30 \mathrm{~min}$ of NJME administration. Mice administered with NJHE showed gradual decrease in their spontaneous movement, motor activity and grip strength $30 \mathrm{~min}$ after oral administration at all dose level $250 \mathrm{mg} / \mathrm{kg}$ b.w. and $500 \mathrm{mg} / \mathrm{kg}$ b.w. Detail summery of general activity and time dose dependent response showing average data score for NJME and NJHE are shown in table 1 and 2.

With VWME there was a decrease in the spontaneous movement, motor response and muscle tone at $250 \mathrm{mg} / \mathrm{kg}$ body weight and $500 \mathrm{mg} / \mathrm{kg}$ b.w. after $30 \mathrm{~min}$ only and also decreased sensorimotor response for pinna at $500 \mathrm{mg} / \mathrm{kg} \mathrm{b} . \mathrm{w}$. after $30 \mathrm{~min}$. Oral administration of VWHE showed that after 30 min spontaneous movement of mice, it gradually decreased at $250 \mathrm{mg} / \mathrm{kg}$ b.w. and $500 \mathrm{mg} / \mathrm{kg}$ b.w. However, decreased in sensorimotor response for pinna, toe pinch and muscle tone were observed at $500 \mathrm{mg} / \mathrm{kg} \mathrm{b} . \mathrm{w}$ after $30 \mathrm{~min}$. of extract administration. Detail summery of general activity and time dose dependent response showing average data score for VWME and VWHE are shown in table 3 and 4.

\section{B. Phenobarbitone induced sleep latency and sleep time}

NJME and NJHE showed significant decreased latency of sleep and produced a prolongation of Phenobarbitone - induced sleeping time in mice at a dose of 250 and $500 \mathrm{mg} / \mathrm{kg} \mathrm{b}$.w. when compared with the control. NJHE showed significant increase in sleep time even at $125 \mathrm{mg} / \mathrm{kg} \mathrm{b.w.} \mathrm{dose} \mathrm{level} \mathrm{(figure1).}$ 
Table 3

General activity and time dose dependent response summery showing average data score for Valeriana wallichii DC Methanolic extract

\begin{tabular}{|c|c|c|c|c|c|c|c|c|c|c|c|c|c|c|c|c|}
\hline \multirow[t]{2}{*}{ VWME } & \multicolumn{16}{|c|}{ Time after administration of different doses of extracts and $0.5 \% \mathrm{CMC}$ to control $(\mathrm{C})$} \\
\hline & \multicolumn{4}{|c|}{ 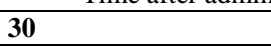 } & \multicolumn{4}{|c|}{60} & \multicolumn{4}{|c|}{120} & \multicolumn{4}{|c|}{180} \\
\hline Dose (mg/kgb.wt) & $\mathbf{C}$ & 125 & 250 & 500 & $\mathbf{C}$ & 125 & 250 & 500 & $\mathbf{C}$ & 125 & 250 & 500 & $\mathbf{C}$ & 125 & 250 & 500 \\
\hline \multicolumn{17}{|l|}{ Behavioural } \\
\hline spontaneous activiy & 4 & 4 & 3 & 2.5 & 4 & 4 & 2.5 & 1.8 & 4 & 4 & 2 & 1.8 & 4 & 4 & 4 & 3.6 \\
\hline Body position & 4 & 4 & 2.5 & 2 & 4 & 4 & 2.8 & 2 & 4 & 4 & 4 & 4 & 4 & 4 & 4 & 4 \\
\hline locomotive activity & 4 & 4 & 3 & 2 & 4 & 4 & 2.5 & 2 & 4 & 4 & 3 & 3.5 & 4 & 4 & 4 & 4 \\
\hline \multicolumn{17}{|c|}{ Motor-affective response } \\
\hline Transfer arousal & 4 & 4 & 3 & 3 & 4 & 4 & 2.8 & 2 & 4 & 4 & 4 & 4 & 4 & 4 & 4 & 4 \\
\hline Touch escape & 4 & 4 & 4 & 2 & 4 & 4 & 3 & 2 & 4 & 4 & 4 & 4 & 4 & 4 & 4 & 4 \\
\hline Positional passivity & 0 & 0 & 0 & 0 & 0 & 0 & 1 & 1 & 0 & 0 & 0 & 1 & 0 & 0 & 0 & 0 \\
\hline \multicolumn{17}{|l|}{ Sensorimotor response } \\
\hline Toe pinch & 4 & 4 & 4 & 3 & 4 & 4 & 4 & 3 & 4 & 4 & 4 & 4 & 4 & 4 & 4 & 4 \\
\hline Corneal & 4 & 4 & 4 & 4 & 4 & 4 & 4 & 4 & 4 & 4 & 4 & 4 & 4 & & 4 & 4 \\
\hline $\begin{array}{l}\text { Pinna } \\
\end{array}$ & 4 & 4 & 3 & 3 & 4 & 4 & 3 & 2 & 4 & 4 & 3 & 2 & 4 & 4 & 4 & 4 \\
\hline \multicolumn{17}{|l|}{ Posture } \\
\hline Tailelevation & 2 & 2 & 2 & 2 & 2 & 2 & 2 & 2 & 2 & 2 & 2 & 2 & 2 & 2 & 2 & 2 \\
\hline \multicolumn{17}{|l|}{ Neurologic } \\
\hline \multicolumn{17}{|l|}{ Muscle tone } \\
\hline Body tone & 4 & 4 & 3 & 2 & 4 & 4 & 3.3 & 2 & 4 & 4 & 4 & 3 & 4 & 4 & 4 & 4 \\
\hline Grip strength & 4 & 4 & 3 & 3 & 4 & 4 & 3 & 2.8 & 4 & 4 & 3.4 & 2.5 & 4 & 4 & 4 & 4 \\
\hline \multicolumn{17}{|l|}{ Equilibrium and gait } \\
\hline Righting reflects & 0 & 0 & 0 & 0 & 0 & 0 & 0 & 0 & 0 & 0 & 0 & 0 & 0 & 0 & 0 & 0 \\
\hline Hypotonic gait & 0 & 0 & 0 & 0 & 0 & 0 & 0 & 0 & 0 & 0 & 0 & 0 & 0 & 0 & 0 & 0 \\
\hline \multicolumn{17}{|l|}{ CNS excitation } \\
\hline Tremors & 0 & 0 & 0 & 0 & 0 & 0 & 0 & 0 & 0 & 0 & 0 & 0 & 0 & 0 & 0 & 0 \\
\hline Twitches & 0 & 0 & 0 & 0 & 0 & 0 & 0 & 0 & 0 & 0 & 0 & 0 & 0 & 0 & 0 & 0 \\
\hline Convulsions & 0 & 0 & 0 & 0 & 0 & 0 & 0 & 0 & 0 & 0 & 0 & 0 & 0 & 0 & 0 & 0 \\
\hline \multicolumn{17}{|l|}{ Autonomic } \\
\hline Eyes: Palpebral closure & 0 & 0 & 0 & 0 & 0 & 0 & 0 & 0 & 0 & 0 & 0 & 0 & 0 & 0 & 0 & 0 \\
\hline \multicolumn{17}{|l|}{ Secretion Excitation } \\
\hline Diarrhoea & _- & _- & _- & _- & _ & _- & _- & _ & _ & _- & _- & _- & _- & _- & _- & _ \\
\hline General & & & & & & & & & & & & & & & & \\
\hline Piloerection & 0 & 0 & 0 & 0 & 0 & 0 & 0 & 0 & 0 & 0 & 0 & 0 & 0 & 0 & 0 & 0 \\
\hline Hypothermia & & & & + & & & & + & & & & & & & & \\
\hline Skincolour & 4 & 4 & 4 & 4 & 4 & 4 & 4 & 4 & 4 & 4 & 4 & 4 & 4 & 4 & 4 & 4 \\
\hline
\end{tabular}

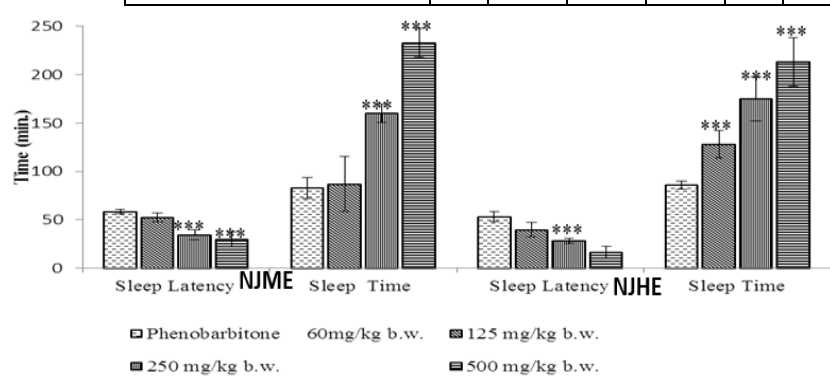

Data presented as Mean $\pm \mathrm{SD}(\mathrm{n}=6) * * * \mathrm{P}<0.001$, compared with that of control group

Fig. 1. Sleep latency and sleep time for NJME and NJHE

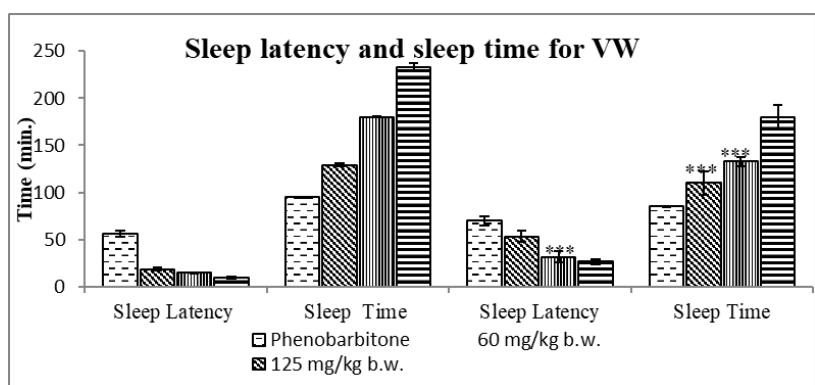

Data presented as Mean $\pm \mathrm{SD}(\mathrm{n}=6) * * * \mathrm{P}<0.001$, compared with that of control group

Fig. 2. Sleep latency and sleep time for VWME and VWHE
The administration of VWME and VWHE produced a prolongation of pentobarbital-induced sleeping time in mice at dose of 125, 250 and $500 \mathrm{mg} / \mathrm{kg}$ b.w. compared to control. A significant decrease in latency of sleep was observed at a dose level 125,250 and $500 \mathrm{mg} / \mathrm{kg}$ b.w. for VWME and 250 and 500 $\mathrm{mg} / \mathrm{kg} \mathrm{b}$.w. for VWHE with respect to control (figure 2).

\section{Walking Assay}

The extract showed no significant difference in the duration of walk in extract administered to animals group compared to the control group. Phenobarbitone administered group showed significant difference in duration taken to cover ruler compared to control group, table 5.

Number of foot slips:

Oral administration of extracts (NJME, NJHE, VWME and VWHE) showed no significant difference in the number of foot slips while covering ruler in extract administered animals group compared to the control group. Phenobarbitone administered group showed significant difference in duration taken to cover ruler compared to control group, table 6. 
Table 4

General activity and time dose dependent response summery showing average data score for Valeriana wallichii DC Hexane extract

\begin{tabular}{|c|c|c|c|c|c|c|c|c|c|c|c|c|c|c|c|c|}
\hline \multirow{3}{*}{$\begin{array}{l}\text { VWHE } \\
\text { Dose (mg/kgb.wt) } \\
\end{array}$} & \multicolumn{16}{|c|}{ Time after administration of different doses of extracts and $0.5 \% \mathrm{CMC}$ to control $(\mathrm{C})$} \\
\hline & \multicolumn{4}{|c|}{30} & \multicolumn{4}{|c|}{60} & \multicolumn{4}{|c|}{120} & \multicolumn{4}{|c|}{180} \\
\hline & $\mathbf{C}$ & 125 & 250 & 500 & $\mathbf{C}$ & 125 & 250 & 500 & $\mathbf{C}$ & 125 & 250 & $\mathbf{5 0 0}$ & $\mathbf{C}$ & 125 & 250 & 500 \\
\hline \\
\hline spontaneous activity & 4 & 4 & 3 & 2 & 4 & 4 & 4 & 1.8 & 4 & 4 & 4 & 2 & 4 & 4 & 4 & 3 \\
\hline Body position & 4 & 4 & 3 & 2 & 4 & 4 & 4 & 2 & 4 & 4 & 4 & 4 & 4 & 4 & 4 & 4 \\
\hline locomotive activity & 4 & 4 & 3 & 2 & 4 & 4 & 3 & 2 & 4 & 4 & 4 & 3.5 & 4 & 4 & 4 & 4 \\
\hline \multicolumn{17}{|c|}{ Motor-affective response } \\
\hline Transfer arousal & 4 & 4 & 4 & 4 & 4 & 4 & 2.8 & 3 & 4 & 4 & 4 & 3 & 4 & 4 & 4 & 4 \\
\hline Touch escape & 4 & 4 & 4 & 2 & 4 & 4 & 4 & 2.1 & 4 & 4 & 4 & 4 & 4 & 4 & 4 & 4 \\
\hline Positional passivity & 0 & 0 & 0 & 1 & 0 & 0 & 1 & 1 & 0 & 0 & 0 & 1 & 0 & 0 & 0 & 0 \\
\hline \multicolumn{17}{|l|}{ Sensorimotor response } \\
\hline Toe pinch & 4 & 4 & 4 & 3 & 4 & 4 & 3 & 3 & 4 & 4 & 4 & 4 & 4 & 4 & 4 & 4 \\
\hline Corneal & 4 & 4 & 4 & 4 & 4 & 4 & 3.5 & 4 & 4 & 4 & 3.3 & 2.8 & & & & \\
\hline $\begin{array}{l}\text { Pinna } \\
\end{array}$ & 4 & 4 & 4 & 3 & 4 & 4 & 3 & 2 & 4 & 4 & 3 & 3 & 4 & 4 & 4 & 4 \\
\hline \multicolumn{17}{|l|}{ Posture } \\
\hline Tailelevation & 2 & 2 & 2 & 2 & 2 & 2 & 2 & 2 & 2 & 2 & 2 & 2 & 2 & 2 & 2 & 2 \\
\hline \multicolumn{17}{|l|}{ Neurologic } \\
\hline \multicolumn{17}{|l|}{ Muscle tone } \\
\hline Body tone & 4 & 4 & 4 & 2 & 4 & 4 & 4 & 3 & 4 & 4 & 4 & 3 & 4 & 4 & 4 & 4 \\
\hline Grip strength & 4 & 4 & 4 & 3 & 4 & 4 & 4 & 2.8 & 4 & 4 & 4 & 2.5 & 4 & 4 & 4 & 4 \\
\hline \multicolumn{17}{|l|}{ Equilibrium and gait } \\
\hline Righting reflects & 0 & 0 & 0 & 0 & 0 & 0 & 0 & 0 & 0 & 0 & 0 & 0 & 0 & 0 & 0 & 0 \\
\hline Hypotonic gait & 0 & 0 & 0 & 0 & 0 & 0 & 0 & 0 & 0 & 0 & 0 & 0 & 0 & 0 & 0 & 0 \\
\hline \multicolumn{17}{|l|}{ CNS excitation } \\
\hline Tremors & 0 & 0 & 0 & 0 & 0 & 0 & 0 & 0 & 0 & 0 & 0 & 0 & 0 & 0 & 0 & 0 \\
\hline Twitches & 0 & 0 & 0 & 0 & 0 & 0 & 0 & 0 & 0 & 0 & 0 & 0 & 0 & 0 & 0 & 0 \\
\hline Convulsions & 0 & 0 & 0 & 0 & 0 & 0 & 0 & 0 & 0 & 0 & 0 & 0 & 0 & 0 & 0 & 0 \\
\hline \multicolumn{17}{|l|}{ Autonomic } \\
\hline Eyes: Palpebral closure & 0 & 0 & 0 & 0 & 0 & 0 & 0 & 0 & 0 & 0 & 0 & 0 & 0 & 0 & 0 & 0 \\
\hline \multicolumn{17}{|l|}{ Secretion Excitation } \\
\hline \multicolumn{17}{|l|}{ Diarrhoea } \\
\hline \multicolumn{17}{|l|}{ General } \\
\hline Piloerection & 0 & 0 & 0 & 0 & 0 & 0 & 0 & 0 & 0 & 0 & 0 & 0 & 0 & 0 & 0 & 0 \\
\hline \multicolumn{2}{|l|}{ Hypothermia } & & & + & & & & + & & & & & & & & \\
\hline Skincolour & 4 & 4 & 4 & 4 & 4 & 4 & 4 & 4 & 4 & 4 & 4 & 4 & 4 & 4 & 4 & 4 \\
\hline
\end{tabular}

Table 5

Number of walking steps to cover ruler

\begin{tabular}{|l|l|l|l|l|l|}
\hline & Phenobarbitone $60 \mathrm{mg} / \mathrm{kg}$ b.w. & Control 0.5\% CMC & $125 \mathrm{mg} / \mathrm{kg}$ b.w. & $250 \mathrm{mg} / \mathrm{kg}$ b.w. & $500 \mathrm{mg} / \mathrm{kg}$ b.w. \\
\hline NJME & $20 \pm 2^{*}$ & $9 \pm 2.4$ & $9.1 \pm 0.94$ & $8.8 \pm 0.1$ & $7.6 \pm 1$ \\
\hline NJHE & $20 \pm 2^{*}$ & $9 \pm 2.4$ & $7.2 \pm 0.1$ & $9.2 \pm 1$ & $9.7 \pm 2$ \\
\hline VWME & $20 \pm 2$ & $9 \pm 2.4$ & $10.1 \pm 0.49$ & $9 \pm 1.2$ & $8 \pm 31$ \\
\hline VWHW & $20 \pm 2$ & $9 \pm 2.4$ & $7.5 \pm 0.11$ & $8 \pm 12$ & $7 \pm 0.2$ \\
\hline
\end{tabular}

Date presented as Mean \pm SD. $(\mathrm{n}=6)$, * significantly different from control at $\mathrm{p}<0.001$ (Dunnett test)

Table 6

Number of foot slips while covering ruler

\begin{tabular}{|l|l|l|l|l|l|}
\hline & Phenobarbitone $60 \mathrm{mg} / \mathrm{kg}$ b.w. & Control 0.5\%CMC & $125 \mathrm{mg} / \mathrm{kgb} . w$. & $250 \mathrm{mg} / \mathrm{kg}$ b.w. & $500 \mathrm{mg} / \mathrm{kg}$ b.w. \\
\hline NJME & $5.2 \pm 0.3^{*}$ & $0.6 \pm 0.25$ & $0.33 \pm 0.2$ & $0.43 \pm 0.3$ & $0.5 \pm 0.25$ \\
\hline NJHE & $5.2 \pm 0.3^{*}$ & $0.6 \pm 0.25$ & $0.45 \pm 0$ & $0.5 \pm 0.2$ & $0.6 \pm 0.3$ \\
\hline VWME & $5.2 \pm 0.3^{*}$ & $0.6 \pm 0.25$ & $0.22 \pm 0.16$ & $0.34 \pm 0.25$ & $0.51 \pm 0.16$ \\
\hline VWHE & $5.2 \pm 0.3^{*}$ & $0.6 \pm 0.25$ & $0.83 \pm 05$ & $0.77 \pm 0.1$ & $0.8 \pm 0.13$ \\
\hline
\end{tabular}

Date presented as Mean \pm SD. $(\mathrm{n}=6), *$ significantly different from control at $\mathrm{p}<0.001$ (Dunnett test)

\section{Conclusion}

Under safety study, all extracts NJME, NJHE, VWME and VWHE were found to be non-toxic up to the dose of 2000 $\mathrm{g} / \mathrm{kgb}$.w. Irwin test showed decrease behavioral response and neurologic response in terms of muscle tone for all extracts at $500 \mathrm{mg} / \mathrm{kg}$ b.w. The reduction of motoraffective sensorimotor responses indicates an action similar to drugs such as major sedative hypnotics (Navorro et al.2011). However, observed behavior was restored within 2-3 hour. Thus, indicating extracts may have short term effect. Phenobarbitone induced sleep behavior is preliminary experiment to know dose dependent response of extracts to sleep behavior. The result of our present study demonstrated that oral administration of extracts produced a dose-dependent decrease in sleep latency and an increase in sleep duration in mice. Walking assay (number of foot slips) is a very sensitive test to measure motor-coordination and effective sedative dose (Stanley et al., 2005). Our all extracts exhibited a non-significant reduction in the number of 
foot slips, although in non-dose dependent manner relative to Phenobarbitone treated group. The result of previous spontaneous motor activity and drug induced sleep activity strongly suggest CNS activity of the extracts which is inline with the study conducted by (Dhingra \& Goyal 2008). The selected extracts also did not show any observable effects on motor coordination in the walking experiment which signify that the sleep effects observed are produced centrally. The change in phenobarbitone induced sleep time is useful experiment for examining effects (stimulatory or inhibitory) on the CNS particularly on GABAergic system (Navarro et al.2011) \& (Tiku \& Maksay 1983). According to the study by ma et al. in 2008 reference compound or drug which increase the sleep duration and decrease the sleep latency over phenobarbitone will also follow the same path and may be due to its effect on GABAergic system (Ma et al.2008). Thus present study has provided information on efficacy of extracts of Nardostachys jatamansi DC and Valleriana wallichii DC on sleep disorders. Baed on our study results and supporting litratures, Nardostachys jatamansi DC and Valeriana wallichii DC have potential to be explored in drug development in various psychosomatic illnesses including surging CovidSomian. These findings would cater to the need of promoting ayurvedic drug than other options of allopathic medication for treatment of sleep disorders and meeting need of pharmaceutical industries.

\section{Acknowledgement}

Special thanks to Dean, My Mentor (Dr. Nancy S. Pandita) and faculties of Sunandan Divatia School of Science, SVKM's NMIMS, Vile Parle (W), Mumbai for their kind support and for providing facilities to perform all the experiments.

\section{References}

[1] Bhattacharyya, D. et al., 2007. Initial exploratory observational pharmacology of Valeriana wallichii on stress management: a clinical report. Nepal Medical College journal: NMCJ, 9(1), pp.36-9.

[2] Dhingra, D. \& Goyal, P.K., 2008. Inhibition of MAO and GABA: probable mechanisms for antidepressant-like activity of Nardostachys jatamansi DC. in mice. Indian journal of experimental biology, 46(4), pp. $212-8$.

[3] Dweck, A.C., 1996. An Introduction to Valerian. In D. P. Houghton, ed. Medicinal and Aromatic Plants Industrial Profile. (King's College London), p. 33.

[4] Gerhard, U. et al., 1996. [Vigilance-decreasing effects of 2 plant-derived sedatives]. Praxis, 85(15), pp. 473-81.

[5] Gilani, A.H. et al., 2005. Antispasmodic and blood pressure lowering effects of Valeriana wallichii are mediated through $\mathrm{K}+$ channel activation. Journal of ethnopharmacology, 100(3), pp. 347-52.
[6] http://www.pubmedcentral.nih.gov/articlerender.fcgi?artid=3118537\&to $\mathrm{ol}=$ pmcentrez\&rendertype $=$ abstract

[7] https://www.express-scripts.com/corporate/articles/americas-state-minduse-mental-health-medications-increasing-spread-coronavirus

[8] Hurley, D. (2020). Sleep Neurologists Call It 'COVID-Somnia'Increased Sleep Disturbances Linked to the Pandemic. Neurology Today, 20(13), 1-26.

[9] Indurwade, N. H. \& Biyani, K. R., 2000. Evaluation of comparative and combined depressive effect of Brahmi, Shankhpushpi and Jatamansi in mice. Indian journal of medical sciences, 54(8), pp. 339-41.

[10] Irwin S., Comprehensive observational assessment, a systematic quantitative procedure for assessing the behavioral and physiologic state of the mouse, Psychopharmacologia, 1968 (13)3, 222- 257.

[11] Jayaweera, D.M.A., 1982. Medicinal Plants (indigenous and Exotic) Used in Ceylon: Rutaceae-Zygophyllaceae, National Science Council of Sri Lanka.

[12] Lorton D et al., Bidirectional communication between the brain and the immune system: Implications for physiological sleep and disorders. Neuroimmuno modulation, 2006, 13, 357-374.

[13] Jing Qi, Jing Xu, Bo-Zhi Li, et al. The evaluation of sleep disturbances for Chinese frontline medical workers under the outbreak of COVID-19, Sleep Med 2020; 72:1-4.

[14] Ma, Y. et al., 2008. Cyclopeptide alkaloid fraction from Zizyphi Spinosi Semen enhances pentobarbital-induced sleeping behaviors. Journal of ethnopharmacology, 117(2), pp. 318-24.

[15] Mendelson WB. A review of the evidence for the efficacy and safety of trazodone in insomnia.J. Clin. Psychiatry. 2005, 66, 469-476.

[16] Navarro, E., Alonso, S.J. \& Navarro, R., 2011. Toxicity and neuropharmacological effects of elenine. Evidence-based complementary and alternative medicine: eCAM, 2011, p.312524.

[17] OECD guidelines, testing of chemicals Acute Toxicity (Fixed Dose Procedure) T. no. 420.

[18] Pearson NJ, Johnson LL, Nahin RL. Insomnia, trouble sleeping, and complementary and alternative medicine: Analysis of the 2002 national health interview survey data. Arch. Intern. Med. 2006, 166, 1775-1782.

[19] Rogers, J. P., Chesney, E., Oliver, D., Pollak, T. A., McGuire, P., FusarPoli, P., Zandi, M. S., Lewis, G., \& David, A. S. (2020). Psychiatric and neuropsychiatric presentations associated with severe coronavirus infections: a systematic review and meta-analysis with comparison to the COVID-19 pandemic. The lancet. Psychiatry, 7(7), 611-627.

[20] Shariq Naeem Syed et al., 2014. A study to evaluate antioxidant and hepatoprotective activity of aqueous extract of roots of Valeriana wallichii in CCl4 induced hepatotoxicity in rats. International Journal of Basic \& Clinical Pharmacology, 3(2), pp. 354-358.

[21] Stanley et al, "The mouse beam walking assay offers more sensitivity over the rotarod in determining motor coordination deficits induced by benzodiazepines," Psychopharmacology, 2005, 19221-227.

[22] Ticku, M.K. \& Maksay, G., 1983. Convulsant/depressant site of action at the allosteric benzodiazepine-GABA receptor-ionophore complex. Life sciences, 33(24), pp. 2363-75.

[23] Trauner, G. et al., 2008. Modulation of GABAA receptors by valerian extracts is related to the content of valerenic acid. Planta medica, 74(1), pp. 19-24.

[24] Zhang, D. et al., 2010. Next-day residual sedative effect after nigh time administration of an over-the-counter antihistamine sleep aid, diphenhydramine, measured by positron emission tomography. Journal of clinical psychopharmacology, 30(6), pp. 694-701. 